\title{
A Haplotype of the GOSR2 Gene Is Associated with Myocardial Infarction in Japanese Men
}

\author{
Shuo Pan,, ${ }^{1,2}$ Tomohiro Nakayama,,3 Naoyuki Sato,' Yoichi Izumi, ${ }^{3}$ Masayoshi Soma,,4 \\ Noriko Aoi, ${ }^{5}$ Yitong $\mathrm{Ma}^{2},{ }^{2}$ Shigeaki Hinohara, ${ }^{6}$ and Nobutaka Doba ${ }^{6}$
}

Aims: The Golgi SNAP Receptor Complex Member 2 (GOSR2) gene is a Golgi-associated soluble factor attachment receptor (SNARE) protein. Some single-nucleotide polymorphisms (SNPs) in the GOSR2 gene have been found to be associated with myocardial infarction (MI). The aim of the present study was to assess the association between the human GOSR2 gene and MI using a haplotype-based case-control study. Methods: A total of $238 \mathrm{MI}$ patients and 284 controls were genotyped for the five SNPs used as genetic markers for the human GOSR2 gene (rs197932, rs3785889, rs197922, rs17608766, and rs16941382). Data were analyzed for three separate groups: the total subjects, men, and women. Results: The overall distribution of the haplotypes in the total subjects and the men was significantly different between the MI patients and the control subjects $(p=0.001$, $p=0.005$, respectively). Additionally, the frequency of the T-G-G haplotype (rs197932-rs3785889-rs197922) for men was significantly lower in the MI patients than in the control subjects $(p=0.040)$. Multiple logistic regression analysis also revealed that the frequency of the subjects with the T-G-G haplotype (homozygous and heterozygous diplotypes) was significantly lower compared with subjects without this haplotype in men after adjustment for the major confounding factors (odds ratio $=0.455, p=0.041)$. Conclusions: The results of this study indicate that the T-G-G haplotype may be a protective genetic marker for MI in Japanese men.

\section{Introduction}

$\mathrm{C}$ ORONARY ARTERY DISEASE, including myocardial infarction (MI), is thought to be a complex multifactorial and polygenic disorder resulting from interactions between an individual's genetic makeup and various environments (Frazier et al., 2005). A variety of gene variants have been shown to be associated with MI (Winkelmann and Hager, 2000; Dowaidar and Settin, 2010).

Golgi SNAP receptor complex member 2 (GOSR2) is a Golgi-associated soluble N-ethylmaleimide-sensitive factor attachment receptor (SNARE) protein that is involved in intraGolgi protein trafficking in multiple tissues (Lowe et al., 1997). It interacts with target-localized SNAREs (t-SNAREs) to allow macromolecules, such as insulin, leptin, and angiotensinogen to move directly between Golgi compartments (Sollner et al., 1993a, 1993b; Rothman, 1994).

Research at the University of California has identified the A allele in rs197922 of the GOSR2 gene as a risk factor for MI (odds ratio $[\mathrm{OR}]=1.17, p=0.032$ ) (Meyer et al., 2009). However, the Atherosclerosis Risk in Communities Study did not find any significant differences, with the OR for the A allele in rs197922 of the GOSR2 gene reported to be 1.08 in whites $(p=0.066)$ and 1.00 in blacks $(p=0.951)$ (Meyer et al., 2009). However, at the present time, there have been no haplotypebased case-control studies that have evaluated the association between the GOSR2 gene and MI. Therefore, the aim of the present study was to assess the associations between the human GOSR2 gene and MI via a haplotype-based case-control study in a Japanese population.

\section{Materials and Methods}

Subjects

Subjects diagnosed with MI $(n=238)$ were recruited at the Nihon University Itabashi Hospital and at other neighboring hospitals in Tokyo. A history of MI was confirmed by the presence of two or more of the following: history of chest

\footnotetext{
${ }^{1}$ Division of Laboratory Medicine, Department of Pathology and Microbiology, Nihon University School of Medicine, Tokyo, Japan.

${ }^{2}$ Division of Coronary Heart Disease, Department of Cardiovascular Medicine, First Affiliated Hospital of Xinjiang Medical University, Urumqi, China.

${ }^{3}$ Division of Nephrology, Hypertension and Endocrinology, Nihon University School of Medicine, Tokyo, Japan.

${ }^{4}$ Division of General Medicine, Department of Medicine, Nihon University School of Medicine, Tokyo, Japan.

${ }^{5}$ Division of Genomic Epidemiology and Clinical Trials, Clinical Trials Research Center, Nihon University School of Medicine, Tokyo, Japan.

${ }^{6}$ Life Planning Center, Tokyo, Japan.
} 
pain indicative of $\mathrm{MI}$, creatine kinase, creatine kinase $\mathrm{MB}$ levels $>3$ times the upper reference limit during a post-MI follow-up, and characteristic electrocardiographic changes at the time of diagnosis (ST segment elevation $>0.1 \mathrm{mV}$ in at least two leads). The elevated levels of cardiac troponins were also used for the criteria of MI. Smokers were defined as current smokers or smokers who had ceased smoking. Nonsmokers were defined as subjects with no history of smoking. Diabetes mellitus was defined on the basis of the World Health Organization (WHO) criteria. Hypertension was defined as blood pressure $\geq 140 / 90 \mathrm{mmHg}$ upon repeated measurements and/or the current use of antihypertensive drugs due to a history of arterial hypertension. Patients diagnosed with secondary hypertension were excluded. Hyperlipidemia was defined as a total plasma cholesterol $\geq 6.5 \mathrm{mmol}$ or plasma triglycerides $\geq 2 \mathrm{mmol}$ and/or the current use of lipid-lowering drugs with an established diagnosis of hyperlipidemia.

Patient age ranged from 31 to 87 years (mean \pm standard deviation [SD], $61.5 \pm 10.0$ years). Japanese subjects $(n=285)$ were enrolled as control subjects, and ranged in age from 66 to 94 years (mean $\pm[S D], 77.9 \pm 4.2$ years). Because the mean age of the control group was older compared with the MI group, the control group was regarded as a supercontrol group. Healthy elderly subjects are more suitable than young or middle-aged subjects when determining the phenotypes of cardiovascular diseases related to aging, as many of these diseases occur late in life. Since MI is an age-influenced disease, it has been shown that a supercontrol group is better than an age-matched control group when investigating MI patients (Aoi et al., 2010). Controls in this study were all members of the New Elder Citizen Movement in Japan, they all lived in Tokyo or in the suburbs of Tokyo, and they all had vascular risk factors such as hypertension, hypercholesterolemia, or diabetes mellitus, but had no history of MI. All controls were confirmed to have grade 0 on the modified Rankin Scale indicating no disability or dependence in the daily activities due to neurological disability such as stroke. Any of the participants found to have cancer or autoimmune diseases were excluded from the study group. All subjects who agreed to participate in the study were evaluated on the basis of a detailed questionnaire that provided information about coronary risk factors such as smoking habits, the presence of diabetes mellitus, or hypertension. Informed consent was obtained from each subject in accordance with the protocol approved by the Human Studies Committee of Nihon University (Yamaguchi et al., 2010).

\section{SNP selection}

The human GOSR2 gene has three transcript variants that encode three different isoforms (isoform A, isoform B, and isoform $\mathrm{C}$ ). Isoform $\mathrm{A}$ of the GOSR2 gene, which has the longest length among the three isoforms, consists of 212 amino acids and is located on chromosome 17q21. This gene consists of approximately 18.25 kilobase pairs (kbp) and contains six exons, which are separated by five introns.

There are 362 SNPs of the human GOSR2 gene listed in the National Center for Biotechnology Information SNP database (www.ncbi.nlm.nih.gov/SNP). In this study, we screened the data on the International HapMap Project website (http:// hapmap.ncbi.nlm.nih.gov/index.html.en) for the tag SNPs of the GOSR2 gene. SNPs with relatively high minor allele frequencies (MAFs) have been shown to be useful as genetic markers in genetic association studies. For this current genetic association study, we selected three SNPs (rs3785889, rs197932, and rs16941382) that had a MAF of > 0.1 among the Japanese population (Fig. 1). rs197932 is located $26 \mathrm{kbp}$ upstream from the start codon in exon 1, whereas rs16941382 is located $25 \mathrm{kbp}$ downstream from the stop codon in exon six (Fig. 1). Meanwhile, we also included rs17608766 and rs197922 from the GOSR2 gene, as these may be associated with blood pressure and coronary heart disease, respectively (Meyer et al., 2009; Ehret et al., 2011).

We designated the five SNPs as SNP1 (rs197932, C_2592633_10), SNP2 (rs3785889, C_2960489_10), SNP3 (rs197922, C_2275273_10), SNP4 (rs17608766, C_33589426_10),
FIG. 1. Structure of the human GOSR2 gene. The gene consists of six exons (boxes) separated by five introns (lines; intergenic regions). Filled boxes indicate the coding regions, while the white box indicated the noncoding region. Arrows indicate the locations of single-nucleotide polymorphisms (SNPs). kbp, kilobase pairs.

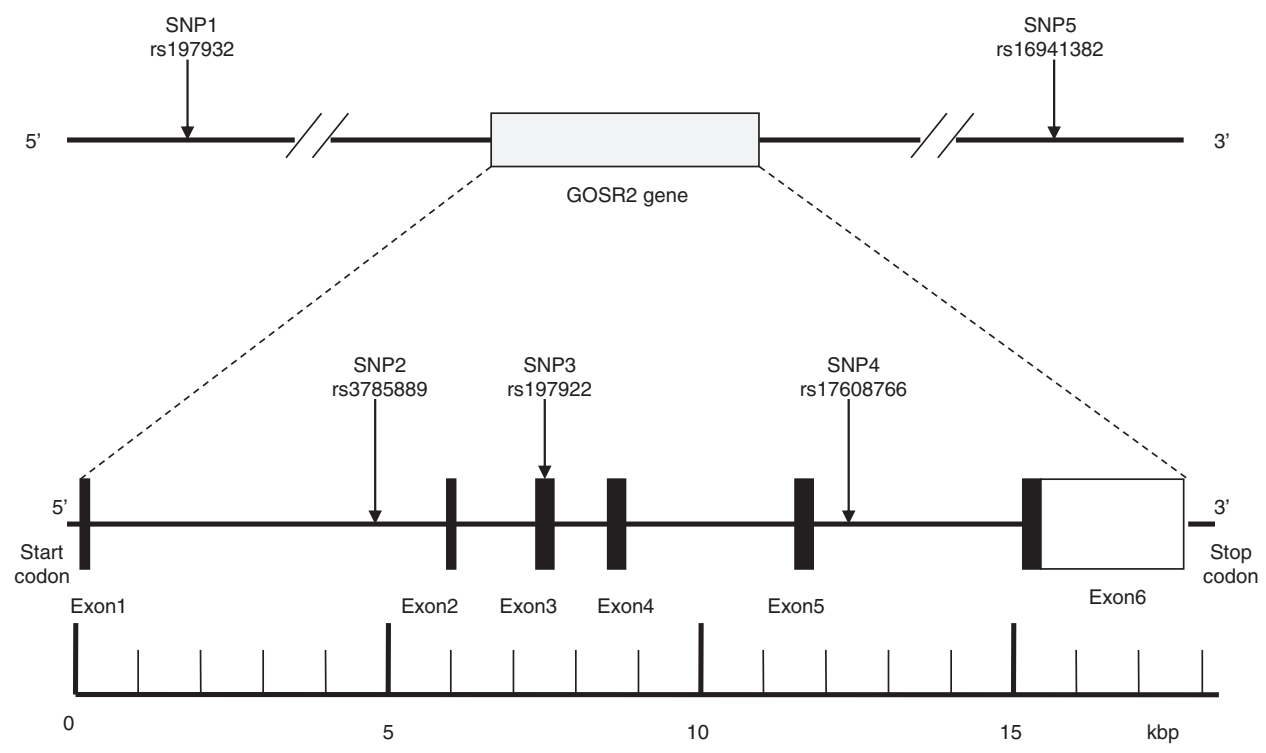


and SNP5 (rs16941382, C_33589395_10), which were in order of increasing the distance from the $5^{\prime}$ end of the gene (Fig. 1).

\section{Genotyping}

Blood samples were collected from all participants, and genomic DNA was extracted from the peripheral blood leukocytes using phenol and the chloroform extraction method (Nakayama et al., 2001).

Genotyping was performed using the TaqMan SNP Genotyping Assay (Applied Biosystems) (Jiang et al., 2012). The mechanism of the TaqMan SNP Genotyping method was as follows. In the first step of the $5^{\prime}$ nuclease assay, allelespecific fluorogenic probes were hybridized to the template. Subsequently, the $5^{\prime}$ nuclease activity of the Taq polymerase makes it possible for discrimination to occur during the polymerase chain reaction (PCR). The probes contain a $3^{\prime}$ minor groove-binding group that hybridizes to singlestranded targets, which have greater sequence specificity than the ordinary DNA probes. This reduces nonspecific probe hybridization, thereby resulting in low background fluorescence for the 5' nuclease PCR assay (TaqMan; Applied Biosystems). Cleavage results in increased emission of a reporter dye. Each $5^{\prime}$ nuclease assay requires two unlabeled PCR primers and two allele-specific probes. Each probe is labeled with two reporter dyes at the $5^{\prime}$ end. In the present study, VIC and FAM were used as the reporter dyes. The primers and probes used in the TaqMan SNP Genotyping Assays (Applied Biosystems) were chosen based on information available at the ABI website (www.appliedbiosystems .com/AB_Home/index.htm).

PCR amplification was performed using $2.5 \mu \mathrm{L}$ of TaqMan Universal Master Mix, No AmpErase UNG $(2 \times)$ (Applied Biosystems) in a $5 \mu \mathrm{L}$ final reaction volume, along with $2 \mathrm{ng}$ DNA, $2.375 \mu \mathrm{L}$ ultrapure water, $0.079 \mu \mathrm{L}$ of the Tris-EDTA (TE) buffer $(1 \times), 0.046 \mu \mathrm{L}$ TaqMan SNP Genotyping Assay Mix $(40 \times)$ containing a $331.2 \mathrm{nM}$ final concentration of primers and a $73.6 \mathrm{nM}$ final concentration of the probes. The thermal cycling conditions were as follows: $50^{\circ} \mathrm{C}$ for $2 \mathrm{~min}$; $95^{\circ} \mathrm{C}$ for $10 \mathrm{~min} ; 50$ cycles of $95^{\circ} \mathrm{C}$ for $15 \mathrm{~s}$; and $60^{\circ} \mathrm{C}$ for $1 \mathrm{~min}$. Thermal cycling was performed using the GeneAmp 9700 system (Applied Biosystems).

Each 96-well plate contained 80 DNA samples of an unknown genotype and four reaction mixtures containing reagents, but no DNA (control). The control samples without DNA are a necessary part of the sequence detection system of the 7700 signal processing system, as outlined in the TaqMan Allelic Discrimination Guide (Applied Biosystems). The plates were read on the sequence detection system 7700 instrument with the endpoint analysis mode of the sequence detection system version 1.6.3 software package (Applied Biosystems). The genotypes were determined visually based on the dye component fluorescent emission data depicted in the X-Y scatter plot of the sequence detection system software. The genotypes were also determined automatically by the signal processing algorithms of the software. The results of each scoring method were saved in two separate output files for later comparison (Livak et al., 1995).

\section{Statistical analysis}

All continuous variables were expressed as mean \pm s.d. Differences in continuous variables between the MI patients

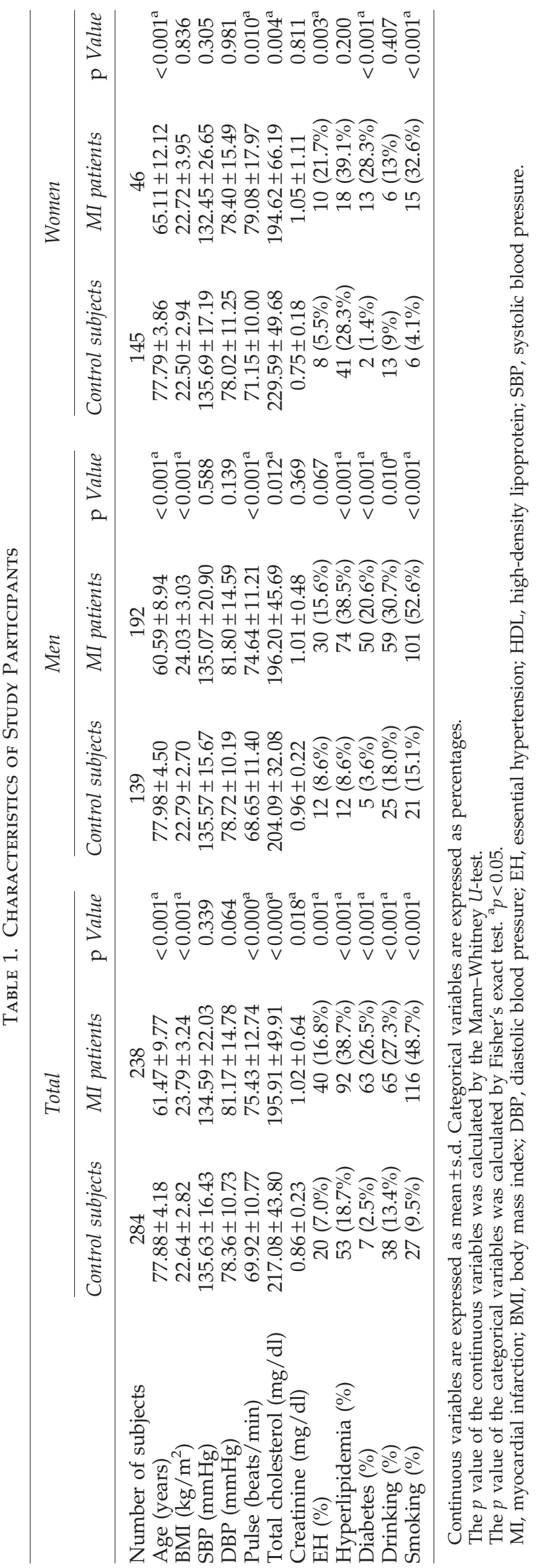


Table 2. Genotyping and Allele Distributions in Control Subjects and Patients with Myocardial Infarction

\begin{tabular}{|c|c|c|c|c|c|c|c|c|c|}
\hline \multirow[b]{2}{*}{ Variants } & \multicolumn{3}{|c|}{ Total } & \multicolumn{3}{|c|}{ Men } & \multicolumn{3}{|c|}{ Women } \\
\hline & $\begin{array}{l}\text { Control } \\
\text { subjects }\end{array}$ & $\begin{array}{c}\text { MI } \\
\text { patients }\end{array}$ & $\underset{\text { Value }}{\mathrm{p}}$ & $\begin{array}{l}\text { Control } \\
\text { subjects }\end{array}$ & $\begin{array}{c}\text { MI } \\
\text { patients }\end{array}$ & $\underset{\text { Value }}{\mathrm{p}}$ & $\begin{array}{l}\text { Control } \\
\text { subjects }\end{array}$ & $\begin{array}{c}\text { MI } \\
\text { patients }\end{array}$ & $\underset{\text { Value }}{\mathrm{p}}$ \\
\hline \multicolumn{10}{|c|}{ rs197932(SNP1) } \\
\hline \multicolumn{10}{|c|}{ Genotyping } \\
\hline $\mathrm{CC}^{\circ}$ & $26(9.2 \%)$ & $19(8.0 \%)$ & & $10(7.2 \%)$ & $12(6.2 \%)$ & & $16(11.0 \%)$ & $7(15.2 \%)$ & \\
\hline $\mathrm{CT}$ & $112(39.4 \%)$ & $99(41.6 \%)$ & & $52(37.4 \%)$ & $79(41.1 \%)$ & & $60(41.4 \%)$ & $20(43.5 \%)$ & \\
\hline $\mathrm{TI}^{\prime}$ & $146(51.4 \%)$ & $120(50.4 \%)$ & 0.825 & $77(55.4 \%)$ & $101(52.6 \%)$ & 0.782 & $69(47.6 \%)$ & $19(41.3 \%)$ & 0.624 \\
\hline \multicolumn{10}{|c|}{ Dominant model } \\
\hline $\mathrm{TI}^{\prime}$ & $146(51.4 \%)$ & $120(50.4 \%)$ & & $77(55.4 \%)$ & $101(52.6 \%)$ & & $69(47.6 \%)$ & $19(41.3 \%)$ & \\
\hline $\mathrm{CC}+\mathrm{CT}$ & $138(48.6 \%)$ & $118(49.6 \%)$ & 0.861 & $62(44.6 \%)$ & $91(47.3 \%)$ & 0.656 & $76(52.4 \%)$ & $27(58.7 \%)$ & 0.500 \\
\hline \multicolumn{10}{|c|}{ Recessive model } \\
\hline $\mathrm{CC}$ & $26(9.2 \%)$ & $19(8.0 \%)$ & & $10(7.2 \%)$ & $12(6.2 \%)$ & & $16(11.0 \%)$ & $7(15.2 \%)$ & \\
\hline $\mathrm{TT}+\mathrm{CT}$ & $258(90.8 \%)$ & $219(92.0 \%)$ & 0.755 & $129(92.8 \%)$ & $180(93.7 \%)$ & 0.498 & $129(89.0 \%)$ & $39(84.8 \%)$ & 0.443 \\
\hline \multicolumn{10}{|l|}{ Allele } \\
\hline C & $164(28.9 \%)$ & $137(28.8 \%)$ & & $72(25.9 \%)$ & $103(26.8 \%)$ & & $92(31.7 \%)$ & $34(37.0 \%)$ & \\
\hline $\mathrm{T}$ & $404(71.1 \%)$ & $339(71.2 \%)$ & 1.000 & $206(74.1 \%)$ & $281(73.2 \%)$ & 0.858 & $198(68.3 \%)$ & $58(63.0 \%)$ & 0.374 \\
\hline \multicolumn{10}{|c|}{ rs3785889(SNP2) } \\
\hline \multicolumn{10}{|c|}{ Genotyping } \\
\hline AA & 11 (3.9\%) & 14 (5.9\%) & & $4(2.9 \%)$ & $14(7.3 \%)$ & & 7 (4.8\%) & $0(0.0 \%)$ & \\
\hline AG & $101(35.6 \%)$ & $90(37.8 \%)$ & & $55(39.5 \%)$ & $72(37.5 \%)$ & & $46(31.7 \%)$ & $18(39.1 \%)$ & \\
\hline GG & $172(60.6 \%)$ & $134(56.3 \%)$ & 0.446 & $80(57.6 \%)$ & $106(55.2 \%)$ & 0.236 & $92(63.4 \%)$ & $28(60.9 \%)$ & 0.280 \\
\hline \multicolumn{10}{|c|}{ Dominant model } \\
\hline GG & $172(60.6 \%)$ & $134(56.3 \%)$ & & $80(57.6 \%)$ & $106(55.2 \%)$ & & $92(63.4 \%)$ & $28(60.9 \%)$ & \\
\hline $\mathrm{AA}+\mathrm{AG}$ & $112(39.4 \%)$ & $104(43.7 \%)$ & 0.328 & $59(42.5 \%)$ & $86(44.8 \%)$ & 0.737 & $53(36.5 \%)$ & $18(39.1 \%)$ & 0.861 \\
\hline \multicolumn{10}{|c|}{ Recessive model } \\
\hline AA & $11(3.9 \%)$ & $14(5.9 \%)$ & & $4(2.9 \%)$ & $14(7.3 \%)$ & & $7(4.8 \%)$ & $0(0.0 \%)$ & \\
\hline $\mathrm{GG}+\mathrm{AG}$ & $273(96.2 \%)$ & $224(94.1 \%)$ & 0.309 & $135(97.1 \%)$ & $178(92.7 \%)$ & 0.091 & $138(95.1 \%)$ & $46(100.0 \%)$ & 0.351 \\
\hline \multicolumn{10}{|l|}{ Allele } \\
\hline A & $123(21.7 \%)$ & $118(24.8 \%)$ & & $63(22.7 \%)$ & $100(26.0 \%)$ & & $60(20.7 \%)$ & $18(19.6 \%)$ & \\
\hline G & $445(78.3 \%)$ & $358(75.2 \%)$ & 0.239 & $215(77.3 \%)$ & $284(74.0 \%)$ & 0.361 & $230(79.3 \%)$ & $74(80.4 \%)$ & 0.883 \\
\hline \multicolumn{10}{|c|}{ rs197922(SNP3) } \\
\hline Genotyping & & & & & & & & & \\
\hline AA & $70(24.6 \%)$ & $48(20.2 \%)$ & & $38(27.3 \%)$ & $41(21.4 \%)$ & & $32(22.1 \%)$ & $7(15.2 \%)$ & \\
\hline AG & $125(44.0 \%)$ & $121(50.8 \%)$ & & $56(40.3 \%)$ & $94(49.0 \%)$ & & $69(47.6 \%)$ & $27(58.7 \%)$ & \\
\hline GG & $89(31.3 \%)$ & $69(29.0 \%)$ & 0.266 & $45(32.4 \%)$ & $57(29.7 \%)$ & 0.249 & $44(30.0 \%)$ & $12(26.1)$ & 0.424 \\
\hline Dominant $\mathrm{n}$ & hodel & & & & & & & & \\
\hline AG & $125(44.0 \%)$ & $121(50.8 \%)$ & & $56(40.3 \%)$ & $94(49.0 \%)$ & & $69(47.6 \%)$ & $27(58.7 \%)$ & \\
\hline $\mathrm{AA}+\mathrm{GG}$ & $159(56.0 \%)$ & $117(49.2 \%)$ & 0.135 & $83(59.7 \%)$ & $98(51.0 \%)$ & 0.146 & $76(52.1 \%)$ & $19(41.3 \%)$ & 0.236 \\
\hline Recessive $\mathrm{m}$ & odel & & & & & & & & \\
\hline AA & $70(24.6 \%)$ & $48(20.2 \%)$ & & $38(27.3 \%)$ & $41(21.4 \%)$ & & $32(22.1 \%)$ & $7(15.2 \%)$ & \\
\hline $\mathrm{GG}+\mathrm{AG}$ & $214(75.3 \%)$ & $190(79.8 \%)$ & 0.248 & $101(72.7 \%)$ & $151(78.6 \%)$ & 0.240 & $113(77.6 \%)$ & $39(84.8 \%)$ & 0.403 \\
\hline Allele & & & & & & & & & \\
\hline A & $265(47.6 \%)$ & $216(45.5 \%)$ & & 132 (47.5\%) & 176 (45.8\%) & & & $41(44.6 \%)$ & \\
\hline $\mathrm{G}$ & $303(53.3 \%)$ & $259(54.5 \%)$ & 0.709 & $146(52.5 \%)$ & $208(54.2 \%)$ & 0.694 & $157(54.1 \%)$ & $51(55.4 \%)$ & 0.904 \\
\hline rs17608766(SN & P4) & & & & & & & & \\
\hline Genotyping & & & & & & & & & \\
\hline $\mathrm{TT}$ & $284(100.0 \%)$ & $238(100.0 \%)$ & & $139(100.0 \%)$ & $192(100.0 \%)$ & & $145(100.0 \%)$ & $46(100.0 \%)$ & \\
\hline $\mathrm{CT}$ & $0(0.0 \%)$ & $0(0.0 \%)$ & & $0(0.0 \%)$ & $0(0.0 \%)$ & & $0(0.0 \%)$ & $0(0.0 \%)$ & \\
\hline CC & $0(0.0 \%)$ & $0(0.0 \%)$ & - & $0(0.0 \%)$ & $0(0.0 \%)$ & - & $0(0.0 \%)$ & $0(0.0 \%)$ & - \\
\hline Dominant $\mathrm{m}$ & nodel & & & & & & & & \\
\hline $\mathrm{TT}$ & $284(100.0 \%)$ & $238(100.0 \%)$ & & $139(100.0 \%)$ & $192(100.0 \%)$ & & $145(100.0 \%)$ & $46(100.0 \%)$ & \\
\hline $\mathrm{CC}+\mathrm{CT}$ & $0(0.0 \%)$ & $0(0.0 \%)$ & - & $0(0.0 \%)$ & $0(0.0 \%)$ & - & $0(0.0 \%)$ & $0(0.0 \%)$ & - \\
\hline Recessive $\mathrm{m}$ & odel & & & & & & & & \\
\hline CC & $0(0.0 \%)$ & $0(0.0 \%)$ & & $0(0.0 \%)$ & $0(0.0 \%)$ & & $0(0.0 \%)$ & $0(0.0 \%)$ & \\
\hline $\mathrm{TT}+\mathrm{CT}$ & $284(100.0 \%)$ & $238(100.0 \%)$ & - & $139(100.0 \%)$ & $192(100.0 \%)$ & - & $145(100.0 \%)$ & $46(100.0 \%)$ & - \\
\hline Allele & & & & & & & & & \\
\hline C & $0(0.0 \%)$ & $0(0.0 \%)$ & & $0(0.0 \%)$ & $0(0.0 \%)$ & & $0(0.0 \%)$ & $0(0.0 \%)$ & \\
\hline $\mathrm{T}$ & $568(100.0 \%)$ & $476(100.0 \%)$ & - & $278(100.0 \%)$ & $384(100.0 \%)$ & - & $290(100.0 \%)$ & $92(100.0 \%)$ & - \\
\hline
\end{tabular}


TABle 2. (CONTINUED)

\begin{tabular}{|c|c|c|c|c|c|c|c|c|c|}
\hline \multirow[b]{2}{*}{ Variants } & \multicolumn{3}{|c|}{ Total } & \multicolumn{3}{|c|}{ Men } & \multicolumn{3}{|c|}{ Women } \\
\hline & $\begin{array}{l}\text { Control } \\
\text { subjects }\end{array}$ & $\begin{array}{c}\text { MI } \\
\text { patients }\end{array}$ & $\stackrel{\mathrm{p}}{\text { Value }}$ & $\begin{array}{l}\text { Control } \\
\text { subjects }\end{array}$ & $\begin{array}{c}M I \\
\text { patients }\end{array}$ & $\stackrel{\mathrm{p}}{\mathrm{p} a l u e}$ & $\begin{array}{l}\text { Control } \\
\text { subjects }\end{array}$ & $\begin{array}{c}M I \\
\text { patients }\end{array}$ & ${ }_{\text {Value }}^{\mathrm{p}}$ \\
\hline \multicolumn{10}{|c|}{ rs16941382(SNP5) } \\
\hline \multicolumn{10}{|c|}{ Genotyping } \\
\hline $\mathrm{CC}$ & $41(14.4 \%)$ & $33(13.9 \%)$ & & $21(15.1 \%)$ & $28(14.6 \%)$ & & $20(13.8 \%)$ & $5(10.9 \%)$ & \\
\hline CT & $118(41.5 \%)$ & $114(47.9 \%)$ & & $54(38.8 \%)$ & $92(47.9 \%)$ & & $64(44.1 \%)$ & $22(47.8 \%)$ & \\
\hline TT & $125(44.0 \%)$ & $91(38.2 \%)$ & 0.330 & $64(46.0 \%)$ & $72(37.5 \%)$ & 0.234 & $61(42.1 \%)$ & $19(41.3 \%)$ & 0.893 \\
\hline \multicolumn{10}{|c|}{ Dominant model } \\
\hline CT & $118(41.5 \%)$ & $114(47.9 \%)$ & & $54(38.8 \%)$ & $92(47.9 \%)$ & & $64(44.1 \%)$ & $22(47.8 \%)$ & \\
\hline $\mathrm{CC}+\mathrm{TT}$ & $166(58.5 \%)$ & $124(52.1 \%)$ & 0.158 & $85(61.2 \%)$ & $100(52.1 \%)$ & 0.117 & $81(55.9 \%)$ & $24(52.2 \%)$ & 0.735 \\
\hline \multicolumn{10}{|c|}{ Recessive model } \\
\hline CC & $41(14.4 \%)$ & $33(13.9 \%)$ & & $21(15.1 \%)$ & $28(14.6 \%)$ & & $20(13.8 \%)$ & $5(10.9 \%)$ & \\
\hline $\mathrm{TT}+\mathrm{CT}$ & $243(85.6 \%)$ & $205(86.1 \%)$ & 0.900 & $118(84.9 \%)$ & $164(85.4 \%)$ & 1.000 & $125(86.2 \%)$ & $41(89.1 \%)$ & 0.803 \\
\hline \multicolumn{10}{|l|}{ Allele } \\
\hline C & $200(35.2 \%)$ & $180(37.8 \%)$ & & $96(34.5 \%)$ & $148(38.5 \%)$ & & $104(35.9 \%)$ & $32(34.8 \%)$ & \\
\hline $\mathrm{T}$ & $368(64.8 \%)$ & $296(62.2 \%)$ & 0.401 & $182(65.5 \%)$ & $236(61.5 \%)$ & 0.327 & $186(64.1 \%)$ & $60(65.2 \%)$ & 0.901 \\
\hline
\end{tabular}

SNP, single-nucleotide polymorphism.

and control subjects were analyzed using the Mann-Whitney $U$-test. Differences in categorical variables were analyzed using the Fisher's exact test. Differences in distributions of genotypes and alleles between MI patients and control subjects were analyzed using the Fisher's exact test. Based on the genotype data of the genetic variations, we performed haplotype-based case-control analyses using the expectation maximization algorithm (Dempster et al., 1977) and the software SNPAlyze version 3.2 (Dynacom).

When considering the results of a pairwise linkage disequilibrium (LD) analysis, a haplotype-based case-control study needs to be performed. For the analysis to succeed, all variants should be located in one haplotype block, which is indicated by a large $\left|\mathrm{D}^{\prime}\right|$ value between each SNP (near 1). When the $r^{2}$ values are large (near 1 ) for the pairwise variants, one variant is not needed. The LD analysis was performed using four SNP pairs. We used $\left|\mathrm{D}^{\prime}\right|$ values of $>0.25$ to assign SNP locations to one haplotype block. SNPs with an $r^{2}$ value $>0.5$ were selected as tagged.

In the haplotype-based case-control analysis, haplotypes with a frequency of $<0.01$ were excluded. The frequency distribution of the haplotypes was calculated by performing a permutation test using the bootstrap method. In addition, logistic regression analysis was performed to assess the contribution of the major risk factors after constructing diplotypes for each subject by SNPAlyze version 3.2 (Dynacom). Statistical significance was established at $p<0.05$. Statistical analyses were performed using SPSS software for Windows, version 16.0 (SPSS).

\section{Results}

The sample size for the current study was in line with the sample size numbers that have been proposed as being appropriate in these types of the case-control studies (Olson and Wijsman, 1994).

Table 1 shows the clinical characteristics of the study participants. For total subjects, men, and women, the following values were significantly higher for the MI patients as compared to the control subjects: pulse, incidence of diabetes, and smoking. For total subjects and men, the following values were significantly higher for the MI patients as compared to the control subjects: body mass index, pulse, incidence of hyperlipidemia, diabetes, drinking and smoking. No significant difference was observed in either SBP or DBP between the MI patients and the control subjects.

Table 2 shows the distribution of the genotypes and alleles for the five SNPs. The genotype distributions for each of the SNPs were in good agreement with the predicted HardyWeinberg equilibrium values (data not shown). No genotype other than the TT genotype in SNP4 (rs17608766) was observed in each group. For the four other SNPs that were selected for the present study, no differences were noted for the genotype distributions, the dominant and recessive model distributions or the allele distributions in the total, male, and female subjects.

The $\left|\mathrm{D}^{\prime}\right|$ and $r^{2}$ values for the LD patterns are presented in Table 3. All five SNPs are located in one haplotype block, as all of the $\left|\mathrm{D}^{\prime}\right|$ were beyond 0.25 . Because $r^{2}$ for SNP3-SNP5 was $>0.5$ in our study, this meant that SNP3 and SNP5 could not be used for constructing haplotypes simultaneously. Therefore, given that the MAF of SNP3 was larger compared with SNP5, we constructed the haplotypes using SNP1, SNP2, and SNP3.

In the haplotype-based case-control analysis, haplotypes were established through the use of different combinations of

Table 3. Pairwise Linkage Disequilibrium for Four Single-Nucleotide Polymorphisms

\begin{tabular}{llllll}
\hline \multicolumn{5}{c}{$\left|D^{\prime}\right|$ values } \\
\hline$r^{2}$ values & SNP1 & SNP2 & SNP3 & SNP5 \\
& SNP1 & & 0.373 & 0.625 & 0.896 \\
& SNP2 & 0.016 & & 0.798 & 0.915 \\
& SNP3 & 0.138 & 0.154 & & 0.936 \\
& SNP5 & 0.167 & 0.126 & 0.545 & \\
\hline
\end{tabular}

$\left|\mathrm{D}^{\prime}\right|$ above the diagonal and $r^{2}$ below the diagonal.

The shadowed portion indicates $\left|\mathrm{D}^{\prime}\right|>0.25$ and $r^{2}>0.5$. 
Table 4. Haplotype Analysis in Patients with Myocardial Infarction and Control Subjects

\begin{tabular}{|c|c|c|c|c|c|c|c|c|c|c|c|c|c|c|c|}
\hline \multirow[b]{2}{*}{ Haplotype } & \multirow[b]{2}{*}{ SNP1 } & \multirow[b]{2}{*}{ SNP2 } & \multirow[b]{2}{*}{ SNP3 } & \multicolumn{3}{|c|}{ Overall p Value } & \multicolumn{3}{|c|}{ Frequency in total } & \multicolumn{3}{|c|}{ Frequency in men } & \multicolumn{3}{|c|}{ Frequency in women } \\
\hline & & & & Total & Men & Women & $\begin{array}{c}\text { MI } \\
\text { Patients }\end{array}$ & $\begin{array}{l}\text { Control } \\
\text { Subjects }\end{array}$ & p Value & $\begin{array}{c}\text { MI } \\
\text { Patients }\end{array}$ & $\begin{array}{l}\text { Control } \\
\text { Subjects }\end{array}$ & p Value & $\begin{array}{c}\text { MI } \\
\text { Patients }\end{array}$ & $\begin{array}{l}\text { Control } \\
\text { Subjects }\end{array}$ & p Value \\
\hline & & & & $0.001^{\mathrm{a}}$ & $0.005^{\mathrm{a}}$ & 0.551 & & & & & & & & & \\
\hline H1 & $\mathrm{T}$ & G & G & & & & 0.088 & 0.127 & $0.040^{\mathrm{a}}$ & 0.095 & 0.150 & $0.027^{\mathrm{a}}$ & 0.059 & 0.106 & 0.133 \\
\hline $\mathrm{H} 2$ & $\mathrm{C}$ & G & G & & & & 0.215 & 0.208 & 0.743 & 0.194 & 0.168 & 0.401 & 0.300 & 0.246 & 0.256 \\
\hline H3 & $\mathrm{T}$ & A & G & & & & 0.191 & 0.165 & 0.289 & 0.196 & 0.166 & 0.297 & 0.161 & 0.163 & 0.982 \\
\hline $\mathrm{H} 4$ & $\mathrm{C}$ & $\mathrm{A}$ & G & & & & 0.053 & 0.033 & 0.120 & 0.059 & 0.042 & 0.399 & 0.035 & 0.026 & 0.802 \\
\hline H5 & $\mathrm{T}$ & G & A & & & & 0.431 & 0.400 & 0.289 & 0.437 & 0.406 & 0.436 & 0.411 & 0.396 & 0.779 \\
\hline H6 & $\mathrm{C}$ & G & A & & & & 0.219 & 0.475 & $0.022^{\mathrm{a}}$ & 0.018 & 0.050 & $0.021^{\mathrm{a}}$ & 0.035 & 0.451 & 0.610 \\
\hline $\mathrm{H} 7$ & $\mathrm{~T}$ & $\mathrm{~A}$ & $\mathrm{~A}$ & & & & 0.000 & 0.187 & $0.002^{\mathrm{a}}$ & 0.000 & 0.019 & $0.009^{\mathrm{a}}$ & 0.000 & 0.017 & 0.205 \\
\hline
\end{tabular}

Haplotype with frequencies $>0.01$ were estimated using SNPAlyze software.

The $p$ value was calculated by permutation test using the bootstrap method.

${ }^{\mathrm{a}} p<0.05$.

the SNPs (Table 4). For the total subjects and men, the overall distribution of the haplotypes established by SNP1-SNP2SNP3 was significantly different between the MI patients and the control subjects. The frequency of the T-G-G haplotype established by SNP1-SNP2-SNP3 in these two groups was also significantly lower for the MI patients as compared to the control subjects $(p=0.040)$. Moreover, the frequency of the CG-A and T-A-A haplotype established by SNP1-SNP2-SNP3 in these two groups was also significantly lower for the MI patients compared to the control subjects ( $p=0.022$ and $p=0.002$, respectively). For the women, no significant differences were found between the control subjects and MI patients.

The previously described software SNPAlyze version 3.2 was used to analyze the diplotypes in each of the subjects. Significant differences were found when a logistic regression analysis was performed using each of the confounding factors and the diplotype associated with the MI (Table 5). In men, after adjustments for BMI, diabetes mellitus, hyperlipidemia, essential hypertension, smoking and drinking, subjects with the $\mathrm{H} 1$ diplotype ( $\mathrm{H} 1$ homozygote $+\mathrm{H} 1$ heterozygote) were found to have significantly lower chances of having a MI as compared to those without the $\mathrm{H} 1$ diplotype $(\mathrm{OR}=0.455, p=0.041)$.

\section{Discussion}

GOSR2 is a Golgi-associated soluble factor attachment receptor (SNARE) protein involved in intra-Golgi protein traf-

Table 5. Odds Ratios and 95\% Confidence INTERVALS FOR EACH CONFOUNDING FACTOR and Haplotype Associated with MI in Men

\begin{tabular}{lccc}
\hline $\begin{array}{l}\text { Confounding factors } \\
\text { H1 haplotype (T-G-G) }\end{array}$ & Odd ratios & $95 \% \mathrm{CI}$ & $\mathrm{p}$ Value \\
\hline $\begin{array}{l}\text { (homozygote+ } \\
\text { heterozygote) }\end{array}$ & & & 0.455 \\
HL & 5.765 & $2.727-12.188$ & $<0.001^{\mathrm{a}}$ \\
DM & 7.368 & $2.658-20.420$ & $<0.001^{\mathrm{a}}$ \\
EH & 1.291 & $0.537-3.106$ & 0.568 \\
Smoking & 4.849 & $2.497-9.487$ & $<0.001^{\mathrm{a}}$ \\
Drinking & 1.512 & $0.754-3.034$ & 0.244 \\
BMI & 1.135 & $1.021-1.262$ & $0.019^{\mathrm{a}}$ \\
\hline
\end{tabular}

a $p<0.05$.

$\mathrm{DM}$, diabetes mellitus; HL, hyperlipidemia; $\mathrm{CI}$, confidence intervals. ficking that is expressed in multiple tissues and organs. SNAP receptor (SNARE) complexes form a bridge of opposing membranes that promote membrane fusion within the secretory and endosomal pathways (Rothman, 1994; Hay and Scheller, 1997). The atomic structure of a single SNARE complex has been shown to consist of a highly twisted parallel bundle of four amphipathic helices, one from the vesicle protein VAMP, one from the plasma membrane protein syntaxin 1A, and two from the plasma membrane protein SNAP25 (Poirier et al., 1998; Sutton et al., 1998). Most of the SNARE proteins possess either a glutamine or arginine at the deduced position. Although the precise role that SNAREs play in the specific docking and fusion of transport vesicles remains controversial, different types of experiments indicate that SNARE complexes are the core machinery for intracellular membrane fusion. Thus, the trafficking function may have a functional role in multiple cardiovascular diseases such as $\mathrm{EH}$ and MI.

Research by the University of California has identified the A allele in rs197922 of the GOSR2 gene as a risk factor for MI $(\mathrm{OR}=1.17, p=0.032)$ (Meyer et al., 2009). However, the Atherosclerosis Risk in Communities Study did not find any significant difference in relation to the OR for the A allele in rs197922 of the GOSR2 gene reported to be 1.08 in whites and 1.00 in blacks ( $p=0.066, p=0.951)$ (Meyer et al., 2009). In the present study, the frequency of the A allele in rs197922 of the GOSR2 gene was not significantly different between the control subjects and MI patients in the Japanese population $(p=0.709)$. Our results are consistent with the findings reported for American whites and blacks. The International Consortium for Blood Pressure Genome-Wide Association Studies showed that the rs17608766 in GOSR2 was significantly associated with blood pressure. As rs17608766 in GOSR2 may be involved in some of the changes caused by the blood pressure in the cardiovascular system, we hypothesized that these changes could ultimately lead to MI. However, in the current study, there was only one genotype TT in the SNP4 (rs17608766) among the Japanese population. These results were consistent with the data reported for the Japanese population by the International HapMap Project.

For genes with multiple susceptibilities, an analysis based on haplotypes has advantages over an analysis based on individual SNPs, particularly when the linkage 
disequilibria between the SNPs is weak (Morris and Kaplan, 2002). Our study is the first haplotype-based casecontrol study to investigate the association between the human GOSR2 gene and MI in the Japanese population. In our study, we succeeded in identifying a protective haplotype T-G-G of SNP1-SNP2-SNP3 in men. Based on the diplotype and logistic regression analyses, we believe that the protective haplotype (T-G-G) is an independent protective factor for $\mathrm{MI}$ in Japanese men (OR=0.455, $p=0.041)$. Interestingly, the allele that rs197922 provided to establish the T-G-G protective haplotype was the G allele. This result is consistent with the findings of the University of California, which reported that the A allele in rs197922 of the GOSR2 gene was a risk factor for MI (Meyer et al., 2009). Other case-control studies have identified some gene variants that have a gender-specific tendency for MI (Fu et al., 2012). In line with these findings, our haplotype-based case-control study also showed gender specificity for the distribution of the haplotype (men only). Furthermore, we also discovered two protective haplotypes, the C-G-A and T-A-A haplotype, which were established by SNP1-SNP2SNP3 in men $(p=0.022$ and $p=0.002$, respectively). However, the frequency of occurrence of these two haplotypes was too low to have any practical meaning with regard to being a genetic marker.

The mechanism by which GOSR2 may be associated with MI remains unclear. GOSR2 codes for a vesicular Nethylmaleimide sensitive factor attachment protein receptor (v-SNARE) that is involved in intra-Golgi trafficking of vesicles (Hay et al., 1998). v-SNAREs, such as GOSR2, interact with target-localized SNAREs (t-SNAREs) and allow the directed movement of macromolecules, such as insulin, leptin, and angiotensinogen, between Golgi compartments (Sollner, 1993a, 1993b). Due to its trafficking function, the GOSR2 gene may be involved in cardiovascular diseases. Recently, rs17608766 in the GOSR2 gene was reported to be negatively associated with SBP (Beta $=-0.556, p<0.001)$ and DBP (Beta $=-0.129, p=0.017)$ (Ehret et al., 2011). This negative association with blood pressure may prevent arteriosclerosis, which suggests that some of the haplotypes in the GOSR2 gene may be a protective factor of MI. Unfortunately, at the present time, there have yet to be any reports describing such a phenotype or a GOSR2 knockout mouse. Thus, further studies of this variant's association with MI in animal models would be informative.

In conclusion, this is the first time that correlations between the human GOSR2 gene and MI have been examined in the Japanese population. The present data indicate that the T-G-G haplotype of the human GOSR2 gene might be gender-specific protective genetic markers for MI in Japanese men. Additional studies will need to be undertaken to isolate the functional mutations in the GOSR2 gene that are responsible for regulating MI.

\section{Acknowledgments}

We would like to thank Ms. K. Sugama for her excellent technical assistance. This work was supported by a grant from the Ministry of Education, Culture, Sports, Science and Technology of Japan (MEXT)-Supported Program for the Strategic Research Foundation at Private Universities, 2008-2012, JSPS KAKENHI Grant Number 22590538, and a research grant from the Nihon University School of Medicine.

\section{Author Disclosure Statement}

No competing financial interests exist.

\section{References}

Aoi N, Nakayama T, Soma M, et al. (2010) Association of the insulin-like growth factor1 gene with myocardial infarction in Japanese subjects. Hereditas 147:215-224.

Dempster AP, Laird NM, Rubin DB (1977) Maximum likelihood from incomplete data via the EM algorithm. J R Stat Soc 39:122.

Dowaidar M, Settin A (2010) Risk of myocardial infarction related to factor V Leiden mutation: a meta-analysis. Genet Test Mol Biomarkers 14:493-498.

Ehret GB, Munroe PB, Rice KM (2011) Genetic variants in novel pathways influence blood pressure and cardiovascular disease risk. Nature 478:103-109.

Frazier L, Johnson RL, Sparks E (2005) Genomics and cardiovascular disease. Nurs Scholarsh 37:315-321.

Fu Z, Nakayama T, Sato N, et al. (2012) Haplotype-based case study of human CYP4A11 gene and cerebral infarction in Japanese subject. Hereditas 149:91-98.

Hay JC, Scheller RH (1997) SNAREs and NSF in targeted membrane fusion. Curr Opin Cell Biol 9:505-512

Hay JC, Klumperman J, Oorschot V, et al. (1998) Localization, dynamics, and protein interactions reveal distinct roles for ER and golgi SNAREs. J Cell Biol 141:1489-1502.

Jiang J, Nakayama T, Shimodaira M, et al. (2012) A haplotype of the smoothelin gene associated with myocardial infarction in Japanese women. Genet Test Mol Biomarkers 16:1019_ 1026.

Livak KJ, Marmaro J, Todd JA (1995) Towards fully automated genome-wide polymorphism screening. Nat Genet 9:341342.

Lowe SL, Peter F, Subramaniam VN, et al. (1997) A SNARE involved in protein transport through the Golgi apparatus. Nature 389:881-884.

Meyer TE, Shiffman D, Morrison AC, et al. (2009) GOSR2 Lys67Arg is associated with hypertension in whites. Am J Hypertens 22:163-168.

Morris RW, Kaplan NL (2002) On the advantage of haplotype analysis in the presence of multiple disease susceptibility alleles. Genet Epidemiol 23:221-233.

Nakayama T, Soma M, Rahmutula D, et al. (2001) Isolation of the 5 -flanking region of genes by thermal asymmetric interlaced polymerase chain reaction. Med Sci Monit 7:345-349.

Olson JM, Wijsman EM (1994) Reference: design and samplesize considerations in the detection of linkage disequilibrium with a disease locus. Am J Hum Gene 55:574-580.

Poirier MA, Xiao W, Macosko JC, et al. (1998) The synaptic SNARE complex is a parallel four-stranded helical bundle. Nat Struct Biol 5:765-769

Rothman JE (1994) Mechanisms of intracellular protein transport. Nature 372:55-63.

Sollner T, Bennett MK, Whiteheart SW, et al. (1993a) A protein assembly-disassembly pathway in vitro that may correspond to sequential steps of synaptic vesicle docking, activation, and fusion. Cell 75:409-418.

Sollner T, Whiteheart SW, Brunner M, et al. (1993b) SNAP receptors implicated in vesicle targeting and fusion. Nature 362:318-324. 
Sutton RB, Fasshauer D, Jahn R, et al. (1998) High resolution structure, stability, and synaptotagmin binding of a truncated neuronal SNARE complex. Nature 395:347-353

Winkelmann, BR, Hager J (2000) Genetic variation in coronary heart disease and myocardial infarction: methodological overview and clinical evidence. Pharmacogenomics 1: 73-94.

Yamaguchi M, Nakayama T, Fu Z, et al. (2010) The haplotype of the CACNA 1B gene associated with cerebral infarction in Japanese. Hereditas 147:313-319.
Address correspondence to: Tomohiro Nakayama, MD

Division of Laboratory Medicine Department of Pathology and Microbiology Nihon University School of Medicine 30-1 Ooyaguchi-kamimachi, Itabashi-ku Tokyo 173-8610 Japan

E-mail: nakayama.tomohiro@nihon-u.ac.jp 